\title{
Greening Agri-food Value Chains in Emerging Economies
}

\author{
Matthias Stucki and Anél Blignaut
}

\begin{abstract}
Emerging economies play an increasingly important role in global food security. They often rely on fossil fuels, lag behind on food governance and are characterised by subtropical climates, often requiring energy intensive irrigation and refrigerated storage. Mitigation options for agri-food value chains in emerging economies are novel and have substantial sustainability potential. The session on Greening Agri-food Value Chains in Emerging Economies at the 8th International Conference on Life Cycle Management showed the manifold challenges of emerging economies on their transition path to contributing to a sustainable global food system. LCA can support this path by identifying specific environmental hotspots in food value chains as well as by evaluating and prioritising potential solutions from an environmental perspective.
\end{abstract}

\section{Introduction}

Emerging economies such as Brazil, India, China and South Africa play an increasingly important role in global food security since they are among the world's largest producers of crops. Recently, their economies have experienced rapid growth and increased integration into the global economy [1]. Sustainable development in agricultural value chains of emerging economies is thus of high relevance for global food security. While the reduction of environmental impacts of food value chains has been widely studied in industrialised countries, mitigation options for food value chains in emerging economies are new and have substantial sustainability potential. Many emerging economies rely heavily on fossil fuels, lag behind on food governance and are characterised by climate subtropical conditions,

\author{
M. Stucki (ه) \\ Institute of Natural Resource Sciences, Zurich University \\ of Applied Sciences, 8820 Wädenswil, Switzerland \\ e-mail: matthias.stucki@zhaw.ch
}
A. Blignaut
Blue North Sustainability, Stellenbosch, South Africa
(C) The Author(s) 2018
E. Benetto et al. (eds.), Designing Sustainable Technologies,
Products and Policies, https://doi.org/10.1007/978-3-319-66981-6_13 
often requiring energy intensive irrigation and refrigerated storage [2-5]. In order to green agri-food value chains in emerging economies, these specific conditions need to be taken into consideration. Therefore, the development and implementation of sustainable technologies and production methods along the entire agri-food value chain is a crucial step towards a global sustainable food system.

During the session on Greening Agri-food Value Chains in Emerging Economies at the 8th International Conference on Life Cycle Management in Luxembourg in September 2017 successful projects and options for reducing environmental impacts of agri-food value chains in emerging economies were discussed.

\section{Summary of the Session Presentations}

Within the session on Greening Agri-food Value Chains in Emerging Economies five presentations from four different continents were held. Subsequently, each presentation is referenced at the beginning of each section and therefore not repeated again.

\subsection{Rice, Sugarcane and Oil Palm Cultivation in Thailand}

Trakarn Prapaspongsa analysed technology choices by farmers within the rice, sugarcane and oil palm industries in Thailand [6]. An eco-efficiency assessment was performed using the ISO 14045:2012 standard, whilst the environmental assessment was performed using Life Cycle Assessment (LCA).

Overall, rice cultivation had the largest negative impact on terrestrial acidification and marine eutrophication, with land use change (LUC) playing the most important role. Prapaspongsa determined toxicity and marine eutrophication to be most significant in sugarcane production. Significant environmental impacts are related to burning land. In palm oil production, pesticide use has a high impact.

Financial incentives were recommended: for example, higher prices for sugarcane when the fields are not burnt. Environmental impacts in Thailand could be significantly lowered if pesticide use in palm oil production were reduced and if sugarcane producers refrained from field burning practises.

\subsection{Dairy and Maize Farming in South Africa}

Regula Keller from the Zurich University of Applied Sciences conducted a LCA on the South African dairy industry, where she identified environmental impacts and evaluated the environmental mitigation potential of cleantech options [7]. The study 
led to the development of recommendations for sustainable production and the inclusion of datasets in the ecoinvent database.

A methane inhibitor (3NOP) can be used to reduce the enteric emissions of dairy cows, leading to an $18 \%$ reduction in greenhouse gas (GHG) emissions, with no observable trade-off in the other impact categories. Variable Frequency Drives (VFD) that reduce the electricity demand for pumping water, led to a reduction of $34 \%$ of GHG emissions from maize cultivation. The environmental impacts arising from irrigated maize fodder production could be reduced by $47 \%$ by using solar powered irrigation compared to using South African grid electricity. The addition of a methane inhibitor only reduced the climate change impact category but did not have a significant effect on the other impact categories. Additionally, the long-term safety needs to be proven and public acceptance needs to increase.

It was clear that the irrigation of maize for feed production benefitted from the use of both VFD and, to an even greater extent, from solar photovoltaic energy use. All three options can generally be recommended and early implementation of cleantech could potentially have a significant effect. Different cleantech measures could also be combined to minimise the environmental impacts of milk production.

\subsection{Pork Meat Production in South Africa}

Valentina Russo from the University of Cape Town analysed the water footprint of the commercial pork value chain in South Africa [8]. Meat production in South Africa is on the rise and there is a perception that the water footprints of meat products are large. In addition, South Africa is a water stressed country with physical water scarcity predicted by 2040. The goals of this study were to assess the stress-adjusted blue consumptive water footprint in order to locate the environmental hotspots in meat production and to determine whether South Africa should be concerned about meat consumption in regards to water intensity.

The WSI \& AWARE methods were used to determine the water footprint. The water stress index (WSI [9]) relates water consumption to water scarcity in the same watershed and the AWARE method [10] indicates the available water remaining and quantifies the potential of water deprivation, either to humans or to ecosystems.

The study concluded that the centre of South Africa and the Western Cape are hotspots for meat production. Most of the water is used for feed production (43\%) and farming activities (54\%). It was recommended that feed production be located in water management areas that experiences less stress and that practices should move away from irrigation or toward more efficient irrigation systems. Water use, water stress and water efficiency need to be considered in feed optimisation for intensive animal finishing. 


\subsection{Hydrous Ethanol Production from Sugarcane in Brazil}

Monica Alcantara from Odebrecht Agroindustrial determined the carbon and water footprint of hydrous ethanol produced from sugarcane in Brazil [11]. During growth, sugarcane absorbs carbon dioxide at a rate of $28.3 \mathrm{~g} \mathrm{CO}_{2} / \mathrm{MJ}$. The cultivation and harvesting of sugarcane releases $17.8 \mathrm{~g} \mathrm{CO}_{2} / \mathrm{MJ}$, transport with diesel-powered trucks $4.5 \mathrm{~g} \mathrm{CO}_{2} / \mathrm{MJ}$, whilst processing releases $1 \mathrm{~g} \mathrm{CO}_{2} / \mathrm{MJ}$. Finally, burning in a car engine releases $0.6 \mathrm{~g} \mathrm{CO}_{2} / \mathrm{MJ}$. The results of the carbon footprint depend on the inclusion of LUC in the assessment. The water footprint was quantified at $18.41 \mathrm{of}$ water per litre of ethanol produced at the Odebrecht plant including the life cycle stages from agricultural production involving irrigation up to the operation of the Odebrecht plant. Water use was identified as a hotspot for the Odebrecht Agroindustrial company.

\subsection{Emissions from Global Land Use Change and Deforestation}

Jean-Baptiste Bayart from Quantis discussed how to embed LUC in corporate footprints [12], since it contributes around $18 \%$ of global GHG emissions, more than the direct contribution of the agricultural sector (around 13.5\%). The example of soybeans in Argentina showed that more than $5 \mathrm{~kg} \mathrm{CO}$-eq per $\mathrm{kg}$ soybean are released due to land use change. Corporations can only adopt meaningful strategies to avoid deforestation and other types of LUC in order to reach their GHG reduction targets if these effects can be measured in a harmonised way. However, current models have high uncertainty and there are many different models, which can influence the results. A corporate consortium led by Quantis aims at giving recommendations on how to quantify GHG emissions arising from land use change.

For the allocation of GHG emissions from LUC over time, Bayart proposed a model with linear discounting over 20 years. This means that the allocated emissions during the first crop cycle are higher but will reduce over time.

Bayart concluded that their study is a step forward in reaching a consensus on LUC modelling and that significant methodological improvements have been made. The next step for Quantis is the launch of the pilot phase where the model will be tested on products and commodities.

\section{Outcomes of the Session}

The session on Greening Agri-food Value Chains in Emerging Economies at the 8th International Conference on Life Cycle Management showed the manifold challenges of emerging economies on their transition path to contributing to a 
Sustainable global food system

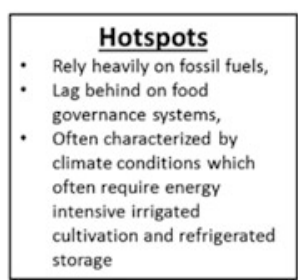
storage

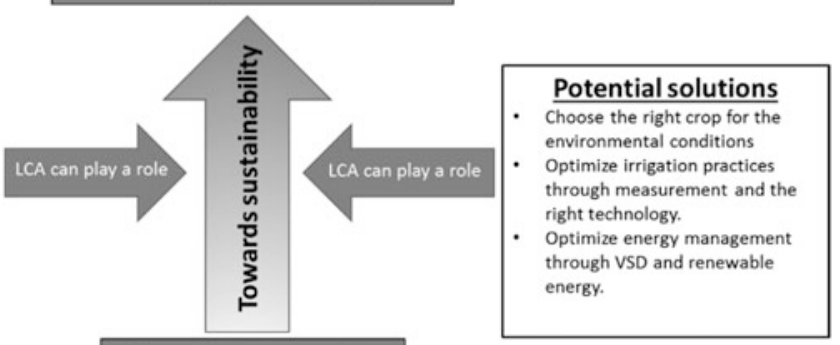

Emerging economies

Fig. 1 The role of LCA in supporting emerging economies on their path to contributing to a sustainable global food system

sustainable global food system. Figure 1 presents a framework on how LCA can support this path by identifying specific environmental hotspots in food value chains within emerging economies as well as by evaluating and prioritising potential solutions from an environmental perspective.

\section{Future Perspectives}

The contributors to the session highlighted a range of specific recommendations for agri-food value chains in emerging economies. These value chains could be made more environmentally sustainable by including environmental aspects when choosing crops for cultivation and when selecting cultivation systems, by avoiding the burning of residues, by reducing irrigation, by using renewable energy, by transforming degraded land and by avoiding practises, such as deforestation, that lead to land use change. From a LCM perspective, there is a need for more specific background data for life cycle inventories in emerging economies and for more harmonised methodologies to order to enhance comparability.

\section{References}

1. Fan S, Brzeska J, The Role of Emerging Countries in Global Food Security, International Food Policy Research Institute, 2010.

2. Asif M, Muneer T, Energy supply, its demand and security issues for developed and emerging economies, Renew. Sustain. Energy Rev., vol. 11, no. Journal Article, pp. 1388-1413, 2007.

3. Carbon Trust, The emerging Cold Economy. Sustainable solutions for rapidly increasing cooling needs, 2015.

4. Douben N, Ratnayake R.M.W, Characteristic data on river floods and flooding; facts and figures, in Floods, from Defence to Management: Symposium Proceedings of the 3rd 
International Symposium on Flood Defence, Book, Section vols., J. van Alphen, E. van Beek, and M. Taal, Eds. 2006, pp. 19-35.

5. IFPRI, 2014-2015 Global Food Policy Report, International Food Policy Research Institute, Washington, 2015.

6. Prapaspongsa T, Gheewala S.H, Right Product or Technology for Sustainable Agri-Food Value Chains? Lessons Learned from Rice, Sugarcane and Oil Palm Cultivation in Thailand, presented at the 8th International Conference on Life Cycle Management, Luxembourg, 06-Sep-2017.

7. Keller R.L, Eyman L, Wettstein S, von Blottnitz H, Scharfy D, Stucki M, Assessment of Cleantech Options to Mitigate Environmental Impacts of South African Dairy and Maize farming, presented at the 8th International Conference on Life Cycle Management, Luxembourg, 06-Sep-2017.

8. Russo V, et al., Life Cycle Inventories of South Africa Agricultural Products, ecoinvent centre in cooperation with University of Cape Town, Blue North, The Green House and Zurich University of Applied Sciences, Zürich, 2017.

9. Pfister S, Koehler A, Hellweg S, Assessing the environmental impacts of freshwater consumption in LCA, Env. Sci Technol, vol. 43, no. 11, pp. 4098-4104, 2009.

10. Boulay A.-M, et al., The WULCA consensus characterization model for water scarcity footprints: assessing impacts of water consumption based on available water remaining (AWARE), Int. J. Life Cycle Assess., pp. 1-11, Jun. 2017.

11. Sodré C, Alcântara M, Fernandes M, Koszka Kiss B.C, Carbon and water footprint of hydrous ethanol from Brazilian sugarcane produced by Odebrecht Agroindustrial, presented at the 8th International Conference on Life Cycle Management, Luxembourg, 06-Sep-2017.

12. Zollinger M, Dettling J, Rossi V, Humbert S, Bayart J.-B, How to embed land use change/ deforestation-related emissions from corporate supply chains into corporate footprints and corporate GHG targets in an accurate and credible manner, presented at the 8th International Conference on Life Cycle Management, Luxembourg, 06-Sep-2017.

Open Access This chapter is licensed under the terms of the Creative Commons Attribution 4.0 International License (http://creativecommons.org/licenses/by/4.0/), which permits use, sharing, adaptation, distribution and reproduction in any medium or format, as long as you give appropriate credit to the original author(s) and the source, provide a link to the Creative Commons license and indicate if changes were made.

The images or other third party material in this chapter are included in the chapter's Creative Commons license, unless indicated otherwise in a credit line to the material. If material is not included in the chapter's Creative Commons license and your intended use is not permitted by statutory regulation or exceeds the permitted use, you will need to obtain permission directly from the copyright holder.

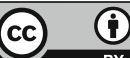

